\title{
The haemodynamic response to myocardial ischaemia in ambulant patients with variant angina
}

\author{
RICHARD D LEVY, LEONARD M SHAPIRO, CHRISTINE WRIGHT, \\ LORNA J MOCKUS, KIM M FOX
}

From the National Heart Hospital, London

SUMMARY The haemodynamic response to myocardial ischaemia in patients with variant angina during ambulatory activity is unknown. Ambulatory pulmonary artery pressure monitoring with a transducer tipped catheter and simultaneous frequency modulated electrocardiograms was used to assess changes in left ventricular function in five male patients (mean age 51.8 years) during variant angina; four patients had coronary artery stenosis and one had normal coronary arteries. Two hundred and seventy hours of ambulatory recordings were analysed. Twenty episodes (12 painful, 8 silent) of ST segment change $>1 \mathrm{~mm}$ occurred. Episodes tended to occur more frequently in the early morning hours. Six episodes of painful ST elevation were associated with a rise in pulmonary artery diastolic pressure. In the remaining episodes ST segment elevation was of shorter duration and there was no rise in pulmonary artery diastolic pressure. Pain was usually a late feature. Silent ST segment elevation occurred at rest and pulmonary artery diastolic pressure increased in all but one episode. Silent exertional ST segment depression was associated with a greater increase in pulmonary artery diastolic pressure than that seen during ST segment elevation. ST segment depression preceded or followed ST segment elevation in two episodes. The onset of ST segment elevation nearly always preceded the onset of a rise in pulmonary artery diastolic pressure. Ergometrine maleate provocation produced a rise in pulmonary artery diastolic pressure in three patients. In one there was no response to $1000 \mu \mathrm{g}$ but spontaneous episodes of ST segment elevation were recorded during ambulatory monitoring. Treadmill exercise resulted in both ST segment elevation and depression with a similar haemodynamic response during both types of electrocardiographic change. When there is important coronary artery disease in two or more vessels ST segment changes may occur in different territories during treadmill exercise and during spontaneous episodes.

Ambulatory pulmonary artery diastolic pressure monitoring is a useful technique for the investigation of variant angina.

In 1959 Prinzmetal et al reported on a group of patients in whom angina occurred at rest and was associated with transient cyclic ST segment elevation. Termed variant angina, this syndrome was thought to be secondary to "temporary occlusion of a large diseased artery with a narrow lumen due to an increase in tonus of the vessel wall". ${ }^{1}$ Later studies have shown that variant angina is part of a spectrum of "vasospastic myocardial ischaemia" and that variant angina may occur in normal coronary arteries or more commonly in those

Requests for reprints to Dr Richard D Levy, National Heart Hospital, Westmoreland Street, London W1M 8BA.

Accepted for publication 15 July 1986 with atherosclerotic coronary artery disease. ${ }^{2} \mathrm{Myo}-$ cardial ischaemia during variant angina is thought to result from a reduction in myocardial oxygen supply. ${ }^{34}$ ST segment depression during myocardial ischaemia in patients with coronary artery disease is associated with a rise in left ventricular end diastolic pressure. $^{5-7}$

Previous studies of the changes in left ventricular end diastolic pressure during variant angina have been confined to patients in the coronary care unit or catheter laboratory. ${ }^{2}$ In the present study we assessed the haemodynamic response during variant angina by means of ambulatory pulmonary artery pressure monitoring. 
Table 1 Clinical and angiographic details of patients with variant angina

\begin{tabular}{|c|c|c|c|c|}
\hline Patient & Age & Sex & Previous myocardial infarction & Coronary and left ventricular angiography \\
\hline $\begin{array}{l}1 \\
2 \\
3\end{array}$ & $\begin{array}{l}40 \\
51 \\
55\end{array}$ & $\begin{array}{l}\mathbf{M} \\
\mathbf{M} \\
\mathbf{M}\end{array}$ & $\begin{array}{l}\text { Inferior } \\
-\end{array}$ & $\begin{array}{l}\text { Good LV function, slightly irregular LAD } \\
\text { Good LV function, } 60 \% \text { stenosis of proximal first diagonal } \\
\text { Good LV function, } 90 \% \text { stenosis of proximal LAD, } 90 \% \\
\text { stenosis of third diagonal }\end{array}$ \\
\hline 4 & 62 & $\mathbf{M}$ & - & $\begin{array}{l}\text { Good LV function, irregularities of LAD and } \mathrm{Cx}, 50 \% \\
\text { stenosis of proximal RCA }\end{array}$ \\
\hline 5 & 51 & $\mathbf{M}$ & - & Good LV function, normal coronary arteriography \\
\hline
\end{tabular}

$\mathrm{LAD}$, left anterior descending coronary artery; $\mathrm{Cx}$, circumflex coronary artery; RCA, right coronary artery; LV, left ventricle.

\section{Patients and methods}

Five male patients (mean age $51 \cdot 8$, range $40-62$ years) were studied. Table 1 summarises the clinical, electrocardiographic, and angiocardiographic data. All patients had a relatively short history of anginal chest pain and four patients had rest pain which was mostly nocturnal. Variant angina was defined as ST segment elevation accompanied by chest pain on ambulatory monitoring or ergometrine maleate provocation. Patients $1,2,4$, and 5 had confirmed coronary artery spasm at the time of ergometrine maleate provocation during coronary angiography.

All antianginal medication other than glyceryl trinitrate was discontinued 48 hours before the study. The protocol was approved by the National Heart Hospital ethics committee and patients gave their informed and written consent.

PULMONARY ARTERY PRESSURE MONITORING A polyurethane 6 French NIH type catheter with a miniature strain gauge transducer mounted on the tip was used. This was calibrated after immersion in saline for one hour before use. The transducer was driven and demodulated by an electrically isolated Gaeltec pre-amplifier. The catheter was introduced percutaneously via a subclavian vein to a proximal pulmonary artery under fluoroscopy in the cardiac catheter laboratory. The pulmonary artery pressure was recorded on an Oxford Medilog I miniature tape recorder that had been modified by the insertion of an AM4 pressure module.

\section{ST SEGMENT MONITORING}

ST segment was monitored on a frequency modulated recorder and leads CM2 and CM5 were recorded. The electrocardiogram was replayed on an Oxford MA20 scanner. Changes in the ST segment were measured $80 \mathrm{~ms}$ after the J point to an accuracy of $0.1 \mathrm{~mm}$ by means of a magnifying lens equipped with a graticule. A change of $1 \mathrm{~mm}$ in the ST segment that lasted $>30$ seconds was considered to be important. ST segment changes were analysed on a beat to beat basis for five minutes before each episode and again up to five minutes after the ST seg- ment had returned to basal levels. The pulmonary artery recorder was linked to the frequency modulated electrocardiogram by an event button that marked both the frequency modulated electrocardiogram and the pulmonary artery trace. ${ }^{8}$

\section{CORONARY ARTERIOGRAPHY}

Coronary arteriography was performed in all patients by the Judkins' technique from the femoral artery with multiple angiographic projections.

ERGOMETRINE MALEATE PROVOCATION TEST

Patient 1 had had a previously positive provocation test and this test was not repeated. Patients 2-5 underwent ergometrine maleate provocation in the catheter laboratory. A 12 lead surface electrocardiogram was recorded continuously (Siemens Mingograph). Incremental doses of ergometrine maleate were given intravenously every five minutes. The initial dose was $25 \mu \mathrm{g}$ and this was increased to $50 \mu \mathrm{g}$ and $100 \mu \mathrm{g}$ and subsequently by $100 \mu \mathrm{g}$ and $200 \mu \mathrm{g}$ up to a maximum to $1000 \mu \mathrm{g}$. The test was terminated if there was chest pain, ST segment changes $>2 \mathrm{~mm}$, severe hypertension, headache, nausea, or vomiting. Angiographic assessment for the presence of coronary artery spasm was made at the end of the test and was followed immediately by 1-3 $\mathrm{mg}$ of intracoronary isosorbide dinitrate. Changes in blood pressure and pulmonary artery pressure were recorded continuously during provocation. Spasm at arteriography was defined as a transient total or subtotal coronary occlusion with delayed distal filling that was reversed by intracoronary nitrates.

\section{AMBULATORY MONITORING}

The patients returned to the ward with a pulmonary artery catheter in situ. Continuous monitoring of pulmonary artery pressure was performed with simultaneous recording of frequency modulated electrocardiograms from leads CM2 and CM5. Patients were instructed to keep diaries during the period of ambulatory monitoring and were asked to note the time of onset and severity of chest discomfort as well as their activity at the time of pain. In 
Table 2 Response to ergometrine maleate provocation

\begin{tabular}{|c|c|c|c|c|c|c|c|}
\hline Patient & $\begin{array}{l}\text { Response to } \\
\text { ergometrine } \\
(+1-)\end{array}$ & $\begin{array}{l}\text { Dose of } \\
\text { ergometrine } \\
(\mu g)\end{array}$ & $\begin{array}{l}\text { Magnitude of } S T \\
\text { segment elevation } \\
(\mathrm{mm})\end{array}$ & $\begin{array}{l}\text { Rise in pulmonary } \\
\text { artery diastolic } \\
\text { pressure }(\mathrm{mm} \mathrm{Hg}) \\
(\%)\end{array}$ & $\begin{array}{l}\text { ECG leads with } \\
\text { maximum change }\end{array}$ & $\begin{array}{l}\text { Painful test } \\
(+1-)\end{array}$ & $\begin{array}{l}\text { Spasm at } \\
\text { angiography }\end{array}$ \\
\hline $\begin{array}{l}1 \\
2 \\
3 \\
4 \\
5\end{array}$ & $\begin{array}{l}+ \\
+ \\
- \\
+\end{array}$ & $\begin{array}{r}100 \\
100 \\
200 \\
1000 \\
100\end{array}$ & $\begin{array}{c}+2.0 \\
+6.5 \\
0 \\
0 \\
+1.5\end{array}$ & $\begin{array}{l}\star \\
12 \cdot 4(117) \\
8(100) \\
0 \\
1 \cdot 5(18 \cdot 8)\end{array}$ & $\begin{array}{l}\text { Anterior } \\
\text { Anterior } \\
- \\
\text { Inferior }\end{array}$ & $\begin{array}{l}+ \\
+ \\
+ \\
+ \\
+\end{array}$ & $\begin{array}{l}\text { LAD } \\
\text { LAD } \\
\text { RCA } \\
\overline{\text { RCA }}\end{array}$ \\
\hline
\end{tabular}

^Previous data without pulmonary artery diastolic pressure recording.

LAD/RCA, left anterior descending and right coronary arteries; ECG, electrocardiogram.

addition, they were asked to press the event marker so that the ST segment and pulmonary artery traces were marked.

\section{EXERCISE TEST}

Exercise testing was performed according to a modified Bruce protocol. ${ }^{9}$ Transducer tipped pulmonary artery pressure and frequency modulated electrocardiogram were recorded continuously. A 12 lead electrocardiogram was recorded on paper at one minute intervals. The exercise test was terminated by angina, dyspnoea, multiple ventricular extrasystoles, hypotension, ST segment depression or elevation $>0.3 \mathrm{mV}$, or exhaustion.

At the end of the period of ambulatory monitoring the pulmonary artery catheter was removed and the pulmonary artery trace was replayed via a PB2 unit and PM3 amplifier. This was displayed on an SE laboratories 6008 oscillograph. The entire period of recording of the pulmonary artery diastolic pressure was displayed and measured on ultraviolet paper with a calibrated scale from a zero reference point. The pulmonary artery diastolic pressure was measured during both painful and painless episodes of ST segment depression on a beat to beat basis five minutes before the onset of the earliest change in pulmonary artery pressure and five minutes after the pulmonary artery diastolic pressure had returned to baseline. The pulmonary artery diastolic pressure was measured at the end of expiration.

\section{STATISTICAL ANALYSIS}

A change of at least three standard deviations from the mean level over a five minute period before any change in pulmonary artery pressure, heart rate, or ST segment was regarded as statistically significant. Wilcoxon rank sum testing was used for analysis.

\section{Results}

\section{ERGOMETRINE MALEATE PROVOCATION}

Four patients had angiographically confirmed coronary artery spasm after ergometrine maleate provocation. In patient 3 chest pain developed after a dose of $200 \mu \mathrm{g}$ in the absence of ST segment changes and patient 4 was unaffected by a total dose of $1000 \mu \mathrm{g}$. Patients 3 and 4 had spontaneous episodes of ST segment elevation. The haemodynamic response to ergometrine maleate was variable (table 2). Pulmonary artery diastolic pressure tended to rise (range 1.5-12.4 mm Hg (18.8-117\%)). Patient 3 had no ST segment change despite a rise in pulmonary artery diastolic pressure of $8 \mathrm{~mm} \mathrm{Hg}(100 \%)$. The most pronounced haemodynamic response to ergometrine maleate occurred in patient 2 (fig 1). A significant rise in pulmonary artery diastolic pressure occurred 102 seconds after the dose of $100 \mu \mathrm{g}$; 42 seconds later the heart rate increased and 66 seconds later there was an abrupt rise in the ST segment. Pain occurred six seconds after the onset of ST segment elevation. The time to maximum pulmonary artery pressure was 220 seconds, maximum heart rate ( 145 beats/minute) 228 seconds, and maximum ST segment elevation 250 seconds. The episode of ST segment elevation was followed by ST segment depression and resolution of pain after isosorbide dinitrate.

\section{EXERCISE TESTING}

Patients 1-4 underwent treadmill testing (table 3). Three patients developed ST segment depression of $>1 \mathrm{~mm}$ and one had ST elevation. In all cases there was a rise in pulmonary artery diastolic pressure. The greatest change in pulmonary artery diastolic pressure $(12.4 \mathrm{~mm} \mathrm{Hg}(775 \%)$ ) occurred in the patient with ST segment elevation of $2.8 \mathrm{~mm}$. This was the only patient in whom chest pain developed. There was a poor correlation between the magnitude and duration of ST segment change $(r=0 \cdot 16, p$ $>0.05$ ) but there was a closer relation between the magnitude and duration of pulmonary artery diastolic pressure $(r=0.74, p<0.05)$. Duration of exercise correlated with the duration of elevation in pulmonary artery diastolic pressure $(r=0.84, p<$ 0.05 ). In patient 3 , who had ST segment elevation, the onset of the change in the ST segment and rise in pulmonary artery diastolic pressure were simultaneous. In two of the other three patients with ST 


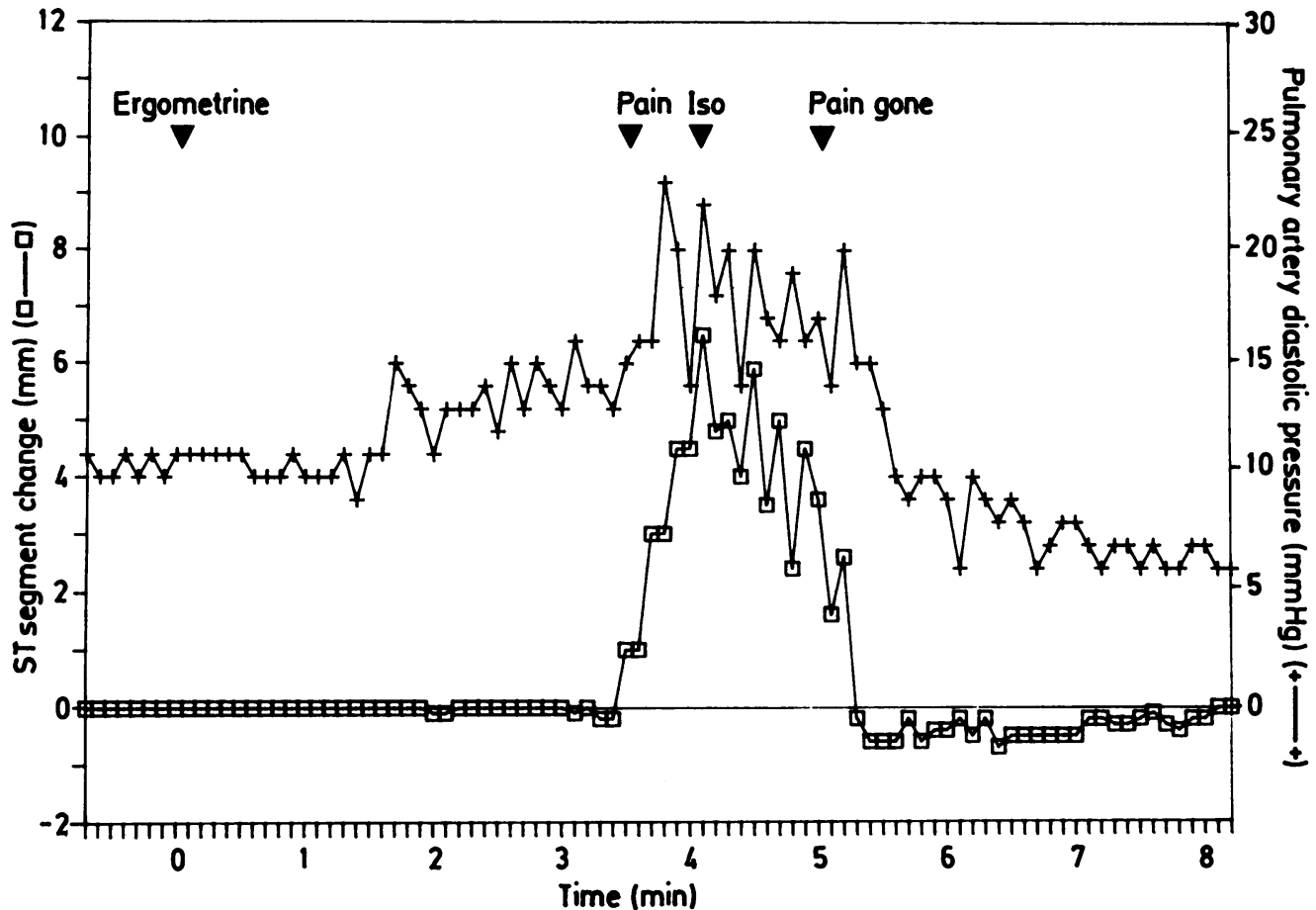

Fig 1 Haemodynamic and electrocardiographic response to a total dose of $100 \mu \mathrm{g}$ of ergometrine maleate in patient 2. A significant rise in pulmonary artery diastolic pressure occurred 102 seconds after the $100 \mu \mathrm{g}$ dose of ergometrine. Forty two seconds later the heart rate increased and 66 seconds later there was an abrupt rise in the $S T$ segment. Pain occurred six seconds after the onset of $S T$ segment elevation. The time to maximum pulmonary artery pressure was 220 seconds and to maximum ST segment elevation 250 seconds, and a maximum heart rate of 145 beats per minute occurred at 228 seconds. The episode of ST segment elevation was followed by $S T$ segment depression and resolution of pain after isosorbide (Iso).

segment depression pulmonary artery diastolic pressure increased before ST segment change; the reverse occurred in the remaining patient. ST segment changes were maximal in lead CM5 in all four patients.

\section{AMBULATORY EPISODES}

Two hundred and seventy hours of ambulatory recording of pulmonary artery pressure and frequency modulated electrocardiogram were analysed and 20 episodes of ST segment change were noted.
Twelve of these were painful and the remainder were not. Figure 2 summarises the diurnal distribution of episodes. Most episodes occurred between 4 am and $8 \mathrm{am}$. Table 4 shows the number of episodes and the duration of ambulatory monitoring for each patient.

\section{PAINFUL EPISODES}

Eleven episodes were associated with ST segment elevation (median 2.15 mm, range 1-3.3) and one with $1 \mathrm{~mm}$ ST depression. Pain was a late feature in

Table 3 Response to treadmill exercise

\begin{tabular}{|c|c|c|c|c|c|c|}
\hline Patient & $\begin{array}{l}\text { Magnitude of } S T \\
\text { segment response } \\
(\mathrm{mm})\end{array}$ & $\begin{array}{l}\text { Rise in pulmonary } \\
\text { artery diastolic } \\
\text { pressure }\left(\mathrm{mm} \mathrm{Hg}_{\mathrm{g}}\right)(\%)\end{array}$ & $\underset{(+1-)}{\text { Pain }}$ & $\begin{array}{l}\text { Duration of } \\
\text { exercise (min) }\end{array}$ & $\begin{array}{l}\text { Duration of } S T \\
\text { segment change } \\
\text { (min) }\end{array}$ & $\begin{array}{l}\text { Duration of raised } \\
\text { pulmonary artery } \\
\text { diastolic pressure } \\
\text { (min) }\end{array}$ \\
\hline $\begin{array}{l}1 \\
2 \\
3 \\
4\end{array}$ & $\begin{array}{l}-2 \cdot 0 \\
-1 \cdot 6 \\
+2 \cdot 8 \\
-2 \cdot 1\end{array}$ & $\begin{array}{c}10(77) \\
5.4(207) \\
12.4(775) \\
3.5(12)\end{array}$ & $\begin{array}{l}- \\
\bar{t} \\
-\end{array}$ & $\begin{array}{l}12 \cdot 3 \\
13 \\
5 \cdot 2 \\
9 \cdot 5\end{array}$ & $\begin{array}{r}36 \cdot 5 \\
2 \cdot 6 \\
14 \cdot 2 \\
11\end{array}$ & $\begin{array}{r}20 \cdot 1 \\
13 \cdot 5 \\
5 \cdot 2 \\
9 \cdot 2\end{array}$ \\
\hline
\end{tabular}




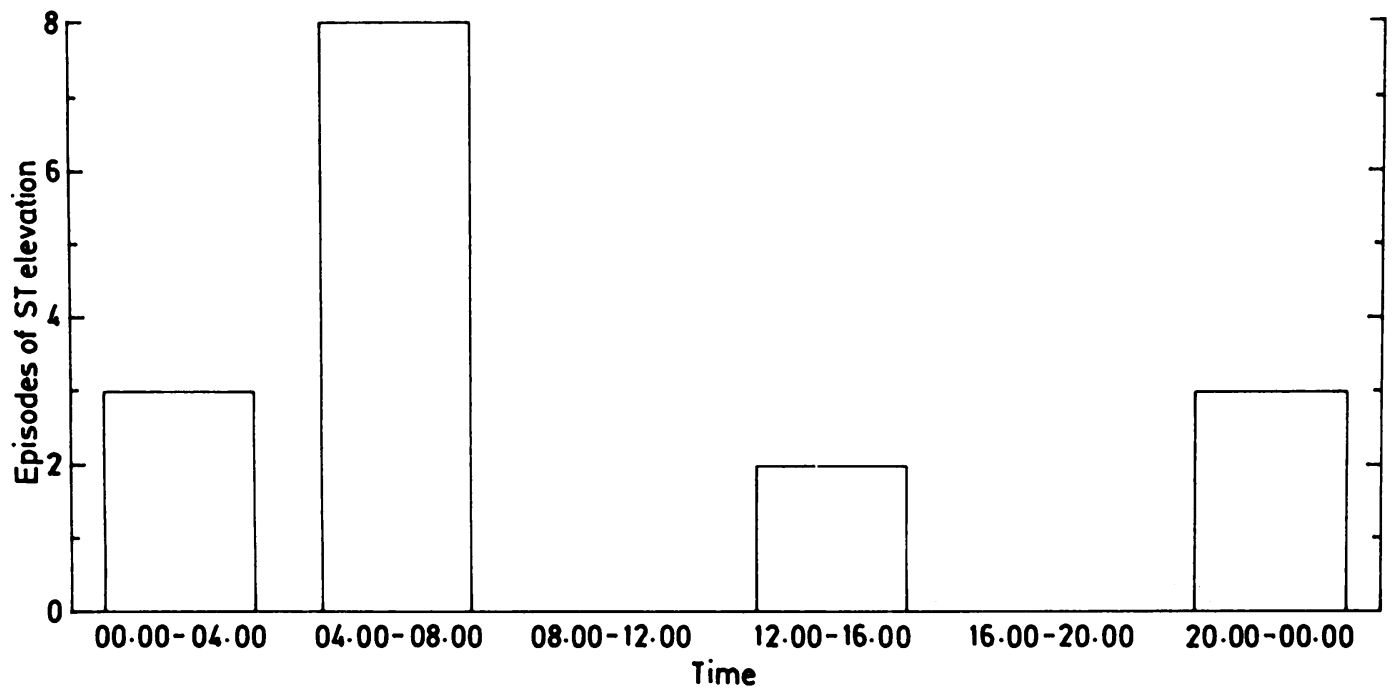

Fig 2 The diurnal distribution of episodes of ST segment elevation. Most episodes occurred in the early morning hours before waking.

nearly all cases, following the point of maximal ST segment elevation or depression. There was a rise in pulmonary artery diastolic pressure during six of the episodes of ST segment elevation. The onset of rise in pulmonary artery diastolic pressure was simultaneous with or followed the rise in the ST segment in all but one episode. Maximum pulmonary artery diastolic pressure and maximum ST segment elevation tended to coincide $(p<0.05)$. Ten of the eleven episodes of ST segment elevation occurred at rest. Glyceryl trinitrate was taken on one occasion and there was no change in pulmonary artery diastolic pressure. ST segment depression preceded or followed ST segment elevation in two episodes. Episodes of ST segment elevation not associated with a rise in pulmonary artery diastolic pressure were of shorter duration (median 1.15 minutes, range $0 \cdot 6-2 \cdot 6$ ) than those episodes with a rise in pulmonary artery diastolic pressure (median 4.65 minutes, range 2-6). ST segment changes during different episodes usually occurred in the same territory in each patient.
PAINLESS EPISODES

Four episodes were associated with ST segment elevation (1.2-2.2 $\mathrm{mm})$ and there was a rise in pulmonary artery diastolic pressure (66-344\%) in three of these episodes that occurred simultaneously with or after the onset of ST segment elevation. There was no rise in pulmonary artery diastolic pressure in the remaining episode (patient 3 ) despite 27 minutes of ST segment elevation reaching a maximum of $2 \cdot 2$ $\mathrm{mm}$. All episodes of ST segment elevation occurred at rest and one episode was followed by ST segment depression. ST segment elevation (median 1.25 minutes, range 0.8-27) lasted longer than the rise in pulmonary artery diastolic pressure (median 0.6 minutes, range 0.4-1) $(p<0.05)$. Four episodes of ST segment depression (1-1.2 $\mathrm{mm}$ ) in the absence of ST segment elevation were recorded. All occurred on exertion and all were associated with a rise in pulmonary artery diastolic pressure (57-275\%). The onset of rise in pulmonary artery diastolic pressure preceded the onset of ST segment depression in two episodes, followed it in one, and was simulta-

Table 4 Number of episodes of ST segment elevation during ambulatory monitoring

\begin{tabular}{llllll}
\hline Patient & $\begin{array}{l}\text { Ambulatory } \\
\text { monitoring }(h)\end{array}$ & $\begin{array}{l}\text { Daytime painful } \\
\text { episodes }\end{array}$ & $\begin{array}{l}\text { Daytime silent } \\
\text { episodes }\end{array}$ & $\begin{array}{l}\text { Nocturnal painful } \\
\text { episodes }\end{array}$ & $\begin{array}{l}\text { Nocturnal painless } \\
\text { episodes }\end{array}$ \\
\hline 1 & 120 & 0 & 1 & 0 & 0 \\
2 & 48 & 0 & 2 & 0 & 0 \\
3 & 30 & 3 & 3 & 0 & 0 \\
4 & 48 & 4 & 2 & 4 & 0 \\
5 & 24 & 0 & 0 & 0 & 0 \\
\hline
\end{tabular}


neous with the remaining episode. The duration of a raised pulmonary artery diastolic pressure on exertion (median 1.95 minutes, range 1.8-2) was longer than that during episodes at rest (median 0.6 minutes, range $0.4-1)(p<0.05)$.

\section{Discussion}

We examined the haemodynamic response to myocardial ischaemia in patients with variant angina by means of simultaneous ambulatory pulmonary artery pressure and ST segment monitoring. Previous studies have been limited to patients confined to bed in the coronary care unit and have used fluid filled catheter systems. ${ }^{23510}$ The transducer tipped catheter technique used in this study is both accurate and allows for full ambulation. ${ }^{8}$ We have shown that changes in pulmonary artery diastolic pressure do not precede ST segment elevation in spontaneous variant angina and this confirms the results of previous studies. ${ }^{2} 1112$

Symptomatic and asymptomatic ST segment changes have been recorded by ambulatory monitoring ${ }^{13}$ and in the coronary care unit. ${ }^{2}$ In our study episodes of symptomatic ST segment elevation were not always associated with a rise in pulmonary artery diastolic pressure. The presence or absence of a rise in pulmonary artery diastolic pressure was related to the duration of ST segment elevation in some patients. Pain was a late feature in most cases. ${ }^{14-17}$ In asymptomatic episodes there was a different haemodynamic response in those with ST segment elevation at rest and in episodes with exertional ST segment depression. The magnitude of pulmonary artery diastolic pressure increase was greatest on exertion.

It has been suggested that episodes of ST segment depression and ST segment elevation occurring within a few minutes of each other show similar haemodynamic patterns. ${ }^{217}$ The interpretation of the haemodynamic changes may be difficult when ST segment depression and elevation occur sequentially.

Episodes of ST segment elevation tend to occur in the early morning. ${ }^{1218-20}$ Eleven of the 20 episodes occurred between 4 am and 8 am. Coronary artery tone may be increased at night and is highest in the early morning ${ }^{21}$ 22 ; however, it has also been shown that there is no increase in sympathetic activity to the heart before the onset of ST segment elevation. ${ }^{23}$ Nocturnal ST segment elevation has been associated with rapid eye movement sleep or changes in sleep pattern ${ }^{24}$ but others have refuted these findings. ${ }^{23} 25$ There is a diurnal variation in pulmonary artery diastolic pressure with a significant rise during the night with peak levels being reached in the early morning hours. ${ }^{26}$ This may be of importance because the raised left ventricular filling pressure in the early morning hours coincides with the largest number of episodes of ST segment elevation at rest.

Ergometrine maleate is an $\alpha$ adrenergic agonist that is used to assess the responsiveness of the coronary arteries to vasoconstrictor stimuli. This has been shown to be a highly specific test for coronary artery spasm in $90-100 \%$ of cases. ${ }^{12}$ Ergometrine maleate increases left ventricular dimension, with resultant poor contractility, ${ }^{27}$ and produces a dramatic reduction in coronary sinus flow consistent with an increase in coronary vascular resistance. ${ }^{2829} \mathrm{We}$ have shown that this test was positive in four of the five patients with variant angina. Patient 4 was totally unresponsive to a dose of $1000 \mu \mathrm{g}$ of ergometrine maleate and yet had documented spontaneous episodes of ST segment elevation on ambulatory monitoring. Patient 3 developed chest pain after $200 \mu \mathrm{g}$ of ergometrine maleate with no ST segment changes. One patient had a dramatic response to a total dose of $100 \mu \mathrm{g}$ of ergometrine maleate with ST segment elevation of $6.5 \mathrm{~mm}$. As a group the change in pulmonary artery diastolic pressure was variable but the response in patient 2 (fig 1) showed that the rise in pulmonary artery diastolic pressure occurred before the heart rate and ST segment changes.

Pharmacological interference with ergometrine maleate may produce coronary artery spasm but appears to have a different haemodynamic effect from that seen during spontaneous episodes. A study in which a transducer tipped catheter was used showed a rise in left ventricular end diastolic pressure which preceded pain and ST segment elevation in a single patient after $330 \mu \mathrm{g}$ of ergometrine maleate. ${ }^{30}$ Patient 1 had only one episode and patient 5 no episodes of ST segment elevation during studies lasting 120 and 48 hours respectively. Both of these patients had positive ergometrine maleate provocation tests with coronary artery spasm at angiography and previously documented episodes of ST segment elevation. Thus disease activity can vary such that patients may have multiple daily attacks for some time followed by a pain free interval of several weeks.

Exercise testing in untreated patients with acute variant angina has been shown to produce ST segment elevation in approximately $30 \%$ of cases, ST segment depression in $30 \%$, and no significant change in the remainder. The ST segment response is not predictive of the presence of or the severity of underlying fixed coronary artery disease. ${ }^{31}$ Four of the five patients in our study performed an exercise test. Three had ST segment depression $>1.5 \mathrm{~mm}$ 
with a rise in pulmonary artery diastolic pressure of $116-207 \%$ (3.5-10 $\mathrm{mm} \mathrm{Hg}$ ). This response to treadmill exercise was similar to that reported in a previous study of 15 patients with documented coronary artery disease and no documented spasm in whom there was a rise in pulmonary artery diastolic pressure (median $5 \mathrm{~mm} \mathrm{Hg}, 69 \%$; range $0-13.8 \mathrm{~mm}$ $\mathrm{Hg}, 0-262 \%$ ). Only one patient in the latter group failed to have a rise in pulmonary artery diastolic pressure in the presence of important ST segment depression. $^{7}$

ST segment depression during an exercise test has been shown to occur in different leads from those showing ST segment elevation at rest, suggesting that the same myocardial region may not be affected by ischaemia at rest and during exercise. ${ }^{1832}$ In one patient (case 4) ST segment depression developed in lead CM5 and the anterior V leads during exercise whereas during several episodes at rest there was ST segment elevation in the inferior leads. Coronary arteriography in this patient showed irregularities in the left anterior descending and circumflex coronary arteries with a $50 \%$ stenosis in the proximal right coronary artery.

Various mechanisms for angina secondary to coronary spasm have been suggested since spasm was first suggested as a possible mechanism for angina pectoris. ${ }^{32} 33$ Angina has been described by Prinzmetal in patients with normal coronary arteries ${ }^{1}$ but is more commonly associated with fixed coronary artery obstruction. ${ }^{23}$ Only one patient in this study had normal coronary arteries.

Coronary blood flow measured by thermodilution techniques has been shown to fall during spontaneous variant angina. ${ }^{29} \mathrm{~A}$ fall in coronary sinus oxygen saturation consistently precedes ST segment elevation, thus indicating that this factor has a causal role in the reduction in coronary blood flow. ${ }^{3}$ Myocardial scintigraphy with thallium-201 ${ }^{1434}$ and I-131 labelled microaggregated human serum albumin $^{35}$ has shown that transmural defects are present during ST segment elevation and absent in the resting state.

Some workers have shown that coronary artery spasm is a frequent cause of angina ${ }^{1836}$ but Quyyumi et al noted that of 100 consecutive patients referred with chest pain for coronary arteriography, only two had ST segment elevation on ambulatory monitoring. ${ }^{37}$ Our study was confined to five patients and has confirmed that ST segment elevation is infrequent and seldom, if ever, occurs other than in the resting state.

The technique of ambulatory pulmonary artery pressure monitoring has provided a means of studying left ventricular function in ambulant patients with variant angina. We have confirmed that changes in pulmonary artery diastolic pressure, reflecting changes in left ventricular end diastolic pressure, do not precede the onset of ST segment elevation in most episodes of variant angina. The response is variable, however, when the changes are provoked by exercise testing or ergometrine maleate.

We thank the Clinical Research Committee of the National Heart and Chest Hospitals for financial support.

\section{References}

1 Prinzmetal M, Kennamer R, Merliss R, Wada T, Bor N. Angina pectoris. I. A variant form of angina pectoris. Am $\mathcal{F}$ Med 1959;27:375-88.

2 Maseri A, Severi S, De Nes M, et al. "Variant" angina: one aspect of a continuous spectrum of vasospastic myocardial ischaemia: pathogenic mechanisms, estimated incidence and clinical and coronary arteriographic findings in 138 patients. Am $\mathcal{F}$ Cardiol 1978;42:1019-35.

3 Chierchia S, Brunelli C, Simonetti I, Lazzari M, Maseri A. Sequence of events in angina at rest: primary reduction in coronary flow. Circulation 1980;61:759-68.

4 Quyyumi AA, Wright CA, Mockus LJ, Fox KM. Mechanisms of nocturnal angina pectoris: importance of increased myocardial oxygen demand in patients with severe coronary artery disease. Lancet 1984;i:1207-9.

5 Parker JO, Di Giorgi S, West RO. The haemodynamics of angina pectoris. In: Proceedings of the international symposium of cardiovascular and respiratory effects of hypoxia Kingston, 1965. Basel and New York: S Karger, 1966:360-74.

6 Figueras J, Singh B, Ganz W, Charuzi Y, Swan H. Mechanism of rest and nocturnal angina: observations during continuous haemodynamic and electrocardiographic monitoring. Circulation 1979;59: 955-68.

7 Levy RD, Shapiro LM, Wright C, Mockus L, Fox KM. Haemodynamic response to myocardial ischaemia during unrestricted activity, exercise testing, and atrial pacing assessed by ambulatory pulmonary artery pressure monitoring. $\mathrm{Br}$ Heart $\mathcal{f}$ 1986;56:12-8.

8 Levy RD, Cunningham AD, Shapiro LM, Wright C, Mockus L, Fox KM. Continuous ambulatory pulmonary artery pressure monitoring: a new method using a transducer tipped catheter and a simple recording system. Br Heart $\mathcal{F}$ 1986;55:336-43.

9 Bruce RA, Blackman JR, Jones JW, Strait G. Exercise testing in adult normal subjects and cardiac patients. Pediatrics 1963;32:742-56.

10 Guazzi M, Polese A, Fiorentini C, Magrini F, Bartorelli C. Left ventricular performance and related haemodynamic changes in Prinzmetal's variant angina pectoris. Br Heart $\mathcal{f} 1971 ; 33: 84-94$.

11 Maseri A, Mimmo R, Chierchia S, Marchesi C, Pesola 
A, L'Abbate A. Coronary artery spasm as a cause of acute myocardial ischaemia in man. Chest 1975;68:625-33.

12 Chierchia S, Lazzari M, Freedman SB, Brunelli C, Maseri A. Impairment of myocardial perfusion and function during painless myocardial ischaemia. $\mathcal{F} \mathrm{Am}$ Coll Cardiol 1983;1:924-30.

13 Schang SL, Pepine C. Transient asymptomatic ST segment depression during daily activity. Am $\mathcal{f}$ Cardiol 1977;39:396-402.

14 Maseri A, Parodi O, Severi S, Pesola A. Transient transmural reduction of myocardial blood flow demonstrated by thallium-201 scintigraphy as a cause of variant angina. Circulation 1976;56:280-8.

15 Guazzi M, Fiorentini C, Polese A, Magrini F. Continuous electrocardiographic recording in Prinzmetal's variant angina pectoris: a report of four cases. Br Heart $\mathcal{f}$ 1970;32:611-6.

16 Guazzi M, Olivari MI, Polese A, Fiorentini C, Magrini F. Repetitive myocardial ischaemia of Prinzmetal type without angina pectoris. Am $\mathcal{f}$ Cardiol 1976;37:923-7.

17 Jouvre A, Guiran JB, Viallet $\mathrm{H}$, et al. Les modifications electrocardiographiques au cours des crises d'angor spontane. Arch Mal Coeur 1969;62:331-51.

18 Araki H, Koiwaya Y, Nakagaki O, Nakamura M. Diurnal variation of ST segment elevation and related arrhythmias on patients with variant angina: a study by ambulatory ECG monitoring. Circulation 1983;67:995-1000.

19 Koroiwa A. Symptomatology of variant angina. $f_{p n}$ Circ $\mathcal{F}$ 1978;42:459-76.

20 Maggini C, Guazelli M, Mauri S, Chierchia S, Cassano GB, Maseri A. Relation of transient myocardial ischaemia to the sleep pattern in patients with "primary angina." In: Maseri A, Klassen GA, Lesch M, eds. Primary and secondary angina pectoris. New York: Grune and Stratton, 1978:157-68.

21 Yasue H, Omote S, Takizawa A, Negao H, Miwa K, Tanaka S. Circadian variation of exercise capacity in patients with Prinzmetal's variant angina: role of exercise induced coronary arterial spasm. Circulation 1979;59:938-48.

22 Ricci DR, Orlick AE, Cipriano PR, Guthaner DF, Harrison DC. Altered adrenergic activity in coronary artery spasm. Insight into mechanism based on study of coronary haemodynamics and the electrocardiogram. Am $\mathcal{F}$ Cardiol 1979;43:1073-9.

23 Chierchia S, Davies G, Berkenboom G, Filippo C, Crean P, Maseri A. Alpha adrenergic receptors and coronary spasm: an elusive link. Circulation 1984;69:8-14.

24 Nowlin JB, Troyer WG, Collins WS, et al. The associ- ation of nocturnal angina pectoris with dreaming. Ann Intern Med 1965;63:1040-6.

25 Maurao S, Harumi K, Katayama S, et al. All night polygraphic studies of nocturnal angina pectoris. $\mathfrak{F}_{p n}$ Heart $\mathcal{F}$ 1972;13:295-306.

26 Levy RD, Shapiro LM, Cunningham AD, Wright C, Mockus L, Fox KM. Diurnal variation in pulmonary artery diastolic pressure: a mechanism for early morning myocardial ischaemia [Abstract]. $\mathrm{Br}$ Heart f 1986;55:518.

27 Distante A, L'Abbate A, Maseri A, Landini L, Michelassi C. Echocardiographic changes in vasospastic angina. In: Lancee CT, ed. Echocardiography. The Hague: Martinus Nijhoff, 1979:119-24.

28 Goldberg S, Lam W, Mudge G. Coronary haemodynamic and metabolic alterations accompanying coronary spasm. Am f Cardiol 1979;43:481-7.

29 Ricci DR, Orlick AE, Doherty PW, Cipriano PR, Harrison DC. Reduction of coronary blood flow during coronary artery spasm occurring spontaneously and after ergonovine maleate. Circulation 1978;57:392-5.

30 Gaash WH, Adyantnaya AV, Wang VH, et al. Prinzmetal's variant angina: haemodynamic and angiographic observations during pain. Am $\mathcal{F}$ Cardiol 1975;35:683-90.

31 Crean PA, Waters DD. Interpreting the exercise electrocardiogram in variant angina. Practical Cardiology 1984;10:107-13.

32 Haywood LJ, Khan AH, de Guzman M. Prinzmetal angina: normal arteries and multifocal electrocardiographic changes. $\mathcal{F} A M A$ 1976;235:53-6.

33 Osler $W$. The Lumleian Lecture on angina pectoris. Lancet 1910;i:697-702.

34 McLaughlin PR, Doherty PW, Martin RP, Goris ML, Harrison DC. Myocardial imaging in a patient with reproducible variant angina. $\mathrm{Am} f$ Cardiol 1977;39:126-9.

35 Berman ND, McLaughlin PR, Huckell VF, et al. Prinzmetal angina with coronary artery spasm: angiographic, pharmacologic, metabolic and radionuclide perfusion studies. $\mathrm{Am} \mathcal{F} \mathrm{Med}$ 1976; 60:727-32.

36 von Arnim T, Höfling B, Schreiber $M$. Characteristics of episodes of ST elevation or ST depression during ambulatory monitoring in patients subsequently undergoing coronary angiography. $\mathrm{Br}$ Heart $\mathfrak{f}$ $1985 ; 54: 484-8$

37 Quyyumi AA, Mockus L, Wright C, Fox KM. Morphology of ambulatory ST segment changes in patients with varying severity of coronary artery disease: investigation of the frequency of nocturnal ischaemia and coronary spasm. $\mathrm{Br}$ Heart $\mathcal{f}$ 1985;53:186-93. 